\title{
A construção da autorrepresentação nos filmes-diário de Jonas Mekas
}

\author{
Cristiane Freitas Gutfreind \\ Rafael Valles
}

Resumo: Este artigo propõe uma reflexão acerca de como os filmes-diário de Jonas Mekas contribuíram para um entendimento mais amplo da autorrepresentação dentro do âmbito cinematográfico. O trabalho parte do pressuposto de que, ao procurar diferentes formas para lidar com a construção do tempo na sua obra, Mekas trouxe novas perspectivas para as narrativas em primeira pessoa.

Palavras-chave: cinema; filme-diário; autorrepresentação; Jonas Mekas.

Abstract: The construction of self-representation in Jonas Mekas' diary-films - This paper proposes a reflection on how the diary films of Jonas Mekas contributed to a broader understanding of the self-representation of the field within the cinematic scope. The work assumes that by searching for different ways to deal with the construction of time in his work, Mekas brought new perspectives to think the first-person narratives.

Keywords: cinema; film-diary; self-representation; Jonas Mekas.

\section{Introdução}

$\mathrm{Na}$ atualidade, presenciamos no cinema autobiografias que encontram o seu protagonismo, sobretudo, em documentários, autorretratos, filmes-ensaio, filmes-diário; são filmes que revelam uma tendência que pode ir desde o resgate de imagens de arquivo caseiras, passando por um registro de busca das suas origens familiares ou mesmo um processo de investigação sobre a morte de um familiar desaparecido em um contexto de regime autoritário. Afirma-se, assim, um contexto onde "não há dúvida de que existe uma recuperação do desejo da autobiografia no cinema" (BERGALA, 2008, p. 27). 
No entanto, essas formas contemporâneas de inscrição do eu não são uma novidade dentro do cenário cinematográfico. Se formos pensar mais especificamente na obra do realizador Jonas Mekas, podemos identificar que essa busca autobiográfica nos remete há décadas. Ao longo dos seus mais de cinquenta anos de carreira no cinema, esse diretor construiu uma obra entorno do filme-diário tornando-se um precursor do gênero e contribuindo para se pensar a autorrepresentação na esfera do audiovisual. Desde filmes como Walden - Diaries, notes and sketches (1964-1969), Reminiscences of a journey to Lithuania (Reminiscências de uma jornada à Lituânia, 1972) e Lost Lost Lost (1976), Mekas fez da sua obra diarística, a construção de uma proposta estética.

Só que antes de Mekas ter utilizado pela primeira vez uma câmera e consolidado essa proposta no cinema, a questão da autorrepresentação foi determinante no diário de exílio que escreveu quando teve que fugir no ano de 1944, aos 22 anos de idade, da Lituânia, seu país de origem. Em nota escrita no dia 17 de abril de 1945, vivendo sob a condição de prisioneiro nos campos de concentração nazistas, durante a Segunda Guerra Mundial, ele afirmou:

Há tanto para ler, para aprender, para ver, para viver. E aqui estou, empurrando um carrinho cheio de bosta de vaca, trabalhando para um alemão. Sem salário. E o tempo passa. Nunca valorizei tanto o tempo como agora. É difícil ler, não é possível se concentrar, cada pensamento corre na sua própria direção. Agora, inclusive durante o dia, não há paz. Os bombardeios voam sem interrupção. Está se tornando perigoso trabalhar nos campos, às vezes cai uma chuva de balas. Quando vejo um avião aproximar-se, solto os cavalos e corro até as cercas. (MEKAS, 2008, p. 86, tradução nossa)

Quarenta anos depois, ao escrever uma apresentação para o que viria a ser o livro I had nowhere to go (1991), Mekas não somente reencontrou os seus escritos do período em que viveu como prisioneiro durante a guerra (1944-1945) e como refugiado no período pós-guerra (1945-1952), como também descobriu um outro fator que assumiu protagonismo: um processo de estranhamento.

Ao reler estes diários já não sei se se trata de verdade ou ficção. Tudo retorna com a nitidez de um sonho ruim que te faz saltar tremendo da cama; leio isto não como minha própria vida, mas como a vida de outro, como se o sofrimento nunca tivesse sido meu. Como poderia ter sobrevivido? Devo estar lendo sobre a vida de outro. (MEKAS, 2008, p. 47, tradução nossa)

Em ambos os fragmentos, um ponto em comum: a escrita em primeira pessoa, o ato de refletir sobre as suas vivências e assumir a si próprio como personagem do seu relato. No entanto, também se observa entre os dois casos duas tendências distintas que viriam a marcar o processo de autorrepresentação na sua obra: enquanto que, no primeiro 
fragmento, Mekas procura afirmar a si próprio como uma testemunha ocular sobre determinados acontecimentos históricos por ele vivenciados, no segundo, ao ressignificar as suas memórias desse mesmo período, ele procura descobrir as implicações que constituem a construção de um outro eu. Se, no primeiro caso, é possível identificar um caráter de denúncia sobre as condições de vida em um campo de concentração nazista, o segundo caso revela um desdobramento causado pelos quarenta anos de distância que separam a escrita do seu diário de exílio, em relação ao Mekas cineasta, escritor e que se tornou cidadão americano, após aportar nos Estados Unidos em 1949. Desprendido do seu contexto como prisioneiro durante a guerra, Mekas assume o desejo em refletir sobre como a passagem do tempo também contribuiu para assumir uma visão distanciada dos seus escritos daquele período.

Exemplos como esses revelam que construir uma escrita em primeira pessoa é ingressar em um caminho de estranhamentos onde as intenções do autor são atravessadas por determinados contextos sócio-históricos e pela inscrição do tempo nesse processo. No limiar entre a interpelação do mundo empírico e a construção de um imaginário, entre as vivências do autor e a sua construção memorialística, aprofundam-se distintas percepções para se pensar a subjetividade contida nos relatos em primeira pessoa.

Para analisarmos a questão da autorrepresentação, a consideraremos em perspectiva ao diário, não somente como forma, mas, sobretudo, como um processo em que a inscrição do tempo se torna fundamental para a construção subjetiva do eu. Diante desse entendimento, buscaremos analisar o diário "na sua condição de escrita atravessada pelo tempo, na sua manifestação fragmentada e calendarizada que assinala o que acontece, como recuperação da experiência no narrar do sujeito que o escreve" (DUHART, 2009, p. 34, tradução nossa). Partiremos, também, da ideia de diário

\begin{abstract}
como um gênero que permite entender a articulação do concreto, do singular e do histórico de uma individualidade como a condição ontológica de caráter mais abstrato e universal do ser humano. Desse modo, o relato do diário íntimo nos permite não só ingressar aos processos de constituição de uma subjetividade particular através da escrita diarística, mas também ingressar, através do quadro da existência humana, vinculados ao problema da temporalidade, da finitude e da morte. (DUHART, 2009, p. 33, tradução nossa)
\end{abstract}

Se vamos aplicar essas questões na esfera cinematográfica, encontramos na obra de Mekas um constante processo reflexivo sobre a construção do diário como uma forma de autorrepresentação. Com trabalhos que revelam uma linha muito tênue entre o objeto artístico em relação às suas vivências pessoais, Mekas não somente expôs fatores autobiográficos na sua obra literária e cinematográfica, mas, sobretudo, procurou pensar as implicações de ordem narrativa e estética geradas por esse processo. Com base nessas problematizações que a obra do cineasta aportou ao tema da autorrepresentação, 
este artigo buscará refletir sobre a importância que os seus filmes-diário possuem para entender a sua trajetória artística e pensar de forma mais ampla a construção dos relatos em primeira pessoa no cinema.

\section{O filme-diário: um processo de tensionamentos}

No artigo O diário: gênese de uma prática, o autor Philippe Lejeune traz uma premissa importante para refletirmos sobre o diário enquanto forma: "o diário não é, em sua origem e, essencialmente, uma obra: é uma prática, e sua finalidade é a vida do seu autor" (LEJEUNE, 2016, p. 11). Lejeune ainda afirma que "o objetivo primeiro do diário não é a produção de efeito sobre o leitor, mas o acúmulo de rastros e o acompanhamento da vida de seu autor. É da ordem do arquivo, não da obra" (LEJEUNE, 2016, p. 14-15). Assim, evidencia nesses dois fragmentos questões contundentes para entendermos o diário como forma. A elaboração de um diário constrói mecanismos de criação que ultrapassam uma ideia de prática? Qual seria o limite que distingue uma prática diarística de uma ambição em fazer dessa escrita a elaboração de uma obra literária (ou no caso de Mekas, cinematográfica?). Onde exatamente se inicia uma obra, onde se termina uma prática?

Ao direcionarmos essas questões para o âmbito cinematográfico e, particularmente, para a obra de Mekas, encontraremos um realizador que contribui para tornar muito tênue essa linha divisória defendida por Lejeune, na medida em que os seus registros fílmicos evidenciam tanto o diário como prática, mas também como arquivo que se torna um material essencial para a construção da sua obra. Como ele próprio afirma, ao filmar breves momentos do seu cotidiano quando recém havia chegado como refugiado aos Estados Unidos, "pensava que o que estava fazendo era praticar. Eu estava me preparando ou tentando manter o contato com a minha câmera, de modo que quando chegasse o dia em que tivesse tempo faria, então, um filme de verdade" (MEKAS, 2013, p. 131).

Só que se o tempo mostrou que Mekas não alcançou o seu objetivo inicial - no sentido de fazer filmes que estivessem mais atrelados aos moldes técnicos, estéticos e narrativos hollywoodianos -, por outro lado, foi por meio dos registros cotidianos da sua vida que o cineasta descobriu o seu próprio caminho como cineasta. Ao construir um caderno de notas com a sua câmera portátil Bolex 16mm, Mekas assumiu premissas narrativas e estéticas que viriam a determinar a construção do que hoje conhecemos como filmes-diário.

Por volta de 1961 ou 1962, vi pela primeira vez todo o material que tinha coletado durante aquele tempo. [...] Enquanto estudava esse material e pensava sobre ele, tornei-me consciente da forma de um filme-diário e, é claro, isso começou a afetar minha maneira de filmar, meu estilo. E em certo sentido isso me ajudou a ter paz de espírito. Eu disse a mim mesmo: "Bem, muito bem - se não tenho tempo para dedicar seis ou sete meses à produção de um filme, não vou me abalar; irei filmar notas curtas, dia a dia, todos os dias". (MEKAS, 2013, p. 132) 
Ao tomar consciência de que esses registros se tornariam determinantes não somente como prática, mas sobretudo como matéria-prima para a construção da sua obra cinematográfica, Mekas descobriu a si mesmo como narrador e personagem por trás dessas imagens. O cineasta assumiu um fator marcadamente autorreferencial, além de mostrar os seus vizinhos nos subúrbios de Nova York, os eventos ou festas realizados pelos exilados lituanos nos Estado Unidos no período pós-guerra, assim como os registros do seu cotidiano e do seu entorno.

Mekas insere-se em um contexto cinematográfico diretamente relacionado ao final dos anos 1950 e início dos anos 1960, quando juntamente com realizadores como Stan Brakhage, Marie Menken, os relatos de cunho autobiográfico começaram a ganhar mais espaço dentro do âmbito audiovisual. Essas produções tinham uma narrativa que transitava entre o ficcional, o documental e o experimental e usufruíam de imagens caseiras e da autorrepresentação. Os filmes de cunho autobiográfico começaram, assim, a buscar novas formas de questionamento da construção da linguagem cinematográfica.

É importante lembrar que o desenvolvimento do cinema autobiográfico surgiu em um ponto específico dentro da história do cinema, envolvendo um processo de ruptura em que a poética da vanguarda foi conjugada com a adesão de técnicas "amadoras" como ferramentas artísticas para o retrato de si. O cinema autobiográfico não diz apenas "eu gostaria de contar a minha vida através do cinema" mas também "basta ao cinema como mídia de massa e como uma atividade industrial e coletiva"(TURIM, 1992, p. 193, tradução nossa).

Mekas procurou ir a fundo nesse contexto. Ao decidir ressignificar um material fílmico tão fragmentário e heterogêneo e de períodos tão distintos entre si, o cineasta começou a construir um entendimento sobre o filme-diário enquanto modalidade cinematográfica, questão esta que acabou abrindo caminho para um entendimento sobre obras posteriores a sua, como é o caso dos diários filmados de David Perlov, Ross McElwee, Anne Charlotte Robertson, entre outros. Na sua essência "o filme-diário confronta as ruínas de um tempo agora irrecuperavelmente perdido" (JAMES, 2013, p. 189). É diante do desejo em revisitar momentos da sua trajetória pessoal, mas, principalmente, refletir narrativamente sobre o processo gerado por este reencontro, que Mekas realizou filmes-diário para se pensar os caminhos da autorrepresentação.

Além disso, faz-se necessário pensar aqui de que forma o filme-diário encaixa-se dentro do âmbito cinematográfico. Assim como o diário literário, os filmes-diário constroem-se com componentes autobiográficos, como é o caso dos registros fílmicos feitos por Mekas, nos quais se documentam, em imagens de forma calendarizada momentos vivenciados e registrados pelo cineasta. No entanto, o que está em jogo aqui é a forma como se procura utilizar esses materiais de caráter autobiográfico, as escolhas estéticas e narrativas que se assumem para a construção dos filmes. 
Mais do que nos informar quem é Mekas ou o que fez na sua vida, seus filmes-diário procuram evidenciar como o cineasta confronta-se com os seus materiais de arquivo. Por trás deste processo reflexivo, Mekas mostra-se mais interessado em desconstruir e ressignificar a si próprio e aos seus registros fílmicos do que propriamente em assumir um caráter que defina categoricamente à sua trajetória. Ele está mais próximo de uma busca ensaística do que de permanecer restrito a uma proposta autobiográfica: "O trabalho de Mekas, como o de Godard, Marker e de outros escritores-cineastas, oferece uma informação importante sobre a ensaística como uma modalidade de inscrição fílmica." (RENOV, 1992, p. 234, tradução nossa). Renov parte do entendimento de que os filmes de Mekas transitam entre um impulso de cunho documental como registrar o real e, ao mesmo tempo, explora a subjetividade do autor no sentido de pensar o seu próprio processo de autorrepresentação, o que conduz a sua obra a um caráter mais ensaístico (RENOV, 1992, p. 228).

Como consequência, as imagens ganham autonomia entre si e o trabalho de montagem se descola de narrativas que procuram um encadeamento cronológico ou causal. Existe uma busca por caminhos que privilegiam a sobreposição dos processos sensoriais aos aspectos argumentativos e biográficos. "Estamos diante de outra abordagem do mundo: uma postura que ensaia novos processos de subjetivação, outros modos de ser e de estar que se conectam a experiências cujo intuito não é mais dominar ou interpretar o mundo" (GONÇALVES, 2014, p. 14).

Trata-se de devires, mais do que histórias, de um conjunto de imagens que aparecem como descrições puras, que emergem como potências sensoriais e afetivas, fora de um finalismo ou de um esquema sensório-motor. Trata-se de um cinema de vidência, uma prática audiovisual que acredita na constituição de um novo olhar sobre o mundo - um olhar que se propõe mais livre, poético, sensorial. (GONÇALVES, 2014, p. 17)

Mekas tornou-se um dos cineastas responsáveis por ampliar esse entendimento dentro do contexto cinematográfico. Se remetermos essas questões à sua obra, isso fica evidente na construção de Walden (1964-1969). Pouco ou nada sabemos sobre quem são as pessoas ou os acontecimentos que Mekas mostra no filme, salvo em breves cartelas que o cineasta coloca sobre a imagem, delimitando determinados locais, pessoas ou datas que aparecem na sequência. Mesmo assim, tais aclarações não se propõem a estabelecer uma melhor explicação sobre quem e o que é mostrado. É o que ocorre, por exemplo, quando Mekas mostra imagens do seu encontro com o cineasta Carl Theodor Dreyer (Fotogramas $01 \mathrm{e}$ 02, $19 \mathrm{~min} 44 \mathrm{seg}$ ), mas pouco sabemos sobre esse encontro além das imagens que se sobrepõem, mostrando distintos ângulos de Dreyer sentado em frente a uma janela com a mão apoiada sobre a mesa e, por momentos, olhando diretamente a câmera. 

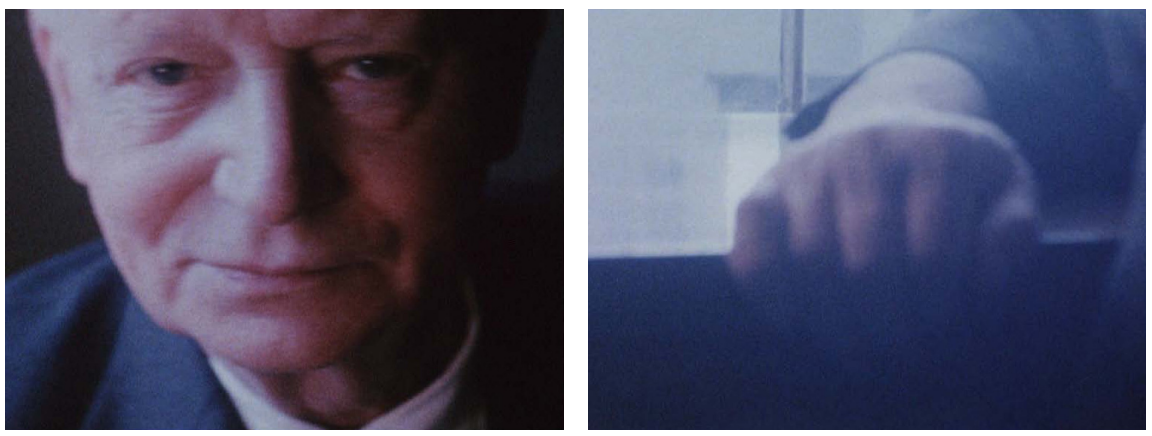

Fotograma1. sequência do filme Walden (MEKAS, 1964-1969). Fotograma 2. sequência do filme Walden (MEKAS, 1964-1969)

Sem diálogo algum, sem o uso da voz em off, sem uma explicação sequer sobre quem é Dreyer, o que Mekas fez foi um retrato do seu encontro com o cineasta suíço. Ao ficarmos reféns pela falta de contextualização - salvo para aqueles espectadores que possuem um conhecimento da história do cinema -, o que sequências como essa propõem é uma busca por se desprender de um entendimento narrativo e privilegiar estados sensoriais.

Filmes como Walden constroem, assim, um importante paradoxo para se pensar a questão da autorrepresentação na sua obra: ao mesmo tempo em que assistimos a imagens que mostram a intimidade de Mekas e das pessoas que ele registra, o cineasta revela quase nada que possibilite elucidar ou melhor entender sobre essa intimidade. Ele gera, por meio dessas imagens, um efeito de estranhamento no espectador, ao compartilhar a sua vida, o seu entorno familiar, mas que, ao mesmo tempo, pouco contextualiza ou revela sobre a sua trajetória. Questões como essas evidenciam que o cineasta procura trabalhar as imagens em uma esfera que transcenda o âmbito biográfico, nos convidando a uma imersão mais sensorial, subjetiva e menos expositiva sobre a sua trajetória.

Em Mekas, esse "caminho da vida como montagem" é uma enorme colcha de trama solta e vazada composta por momentos fugidios, breves registros de paisagens, celebrações, rostos e lugares que o tocaram em algum determinado momento. Da vida de Mekas temos muito pouco. Temos seu rosto, sua voz com seu sotaque inconfundível acrescida durante a edição, temos imagens de páginas de seu diário escrito, mas sabemos pouco ou quase nada dos movimentos que regem sua intimidade, seu casamento ou a vida de seus filhos. (MOURÃO, 2013, p. 14)

Na sua descontinuidade, Mekas privilegia o fragmento, constrói sensorialidades, evidencia um processo de montagem que estabelece novas conexões entre as imagens. Sua resistência em narrar de forma orgânica as suas vivências passadas, termina mostrando o seu desejo em construir algo mais do que uma definição sobre si próprio. É nesse sentido que constatamos o caráter precursor da obra de Mekas e seus desdobramentos na atualidade, na medida em que seus filmes não se restringem ao aspecto biográfico, 
mas à construção de um pensamento sobre si próprio e sobre os seus registros por meio de uma perspectiva ensaística.

\title{
O uso da voz em off e as espessuras do tempo
}

Assim como se propõe a construir caminhos descontínuos e labirínticos entre as imagens, Mekas também procura, por meio da palavra, trazer novos sentidos sobre o seu processo de autorrepresentação. Nos seus filmes-diário, o uso da voz em off' assume protagonismo, seja para dialogar com as imagens, seja simplesmente para contrapô-las ou se dissociar delas. Ele encontra nos pensamentos e rememorações, ditos em primeira pessoa, possibilidades para descobrir distintos matizes na construção de si próprio como personagem dos seus relatos.

No início, o cineasta procurou trazer para a sua obra cinematográfica o caráter de testemunho que produziu no seu diário de exílio, quando teve que fugir do seu país de origem. No filme-diário Reminiscências de uma jornada à Lituânia (MEKAS, 1971-1972), Mekas expõe, com o uso da voz em off, a sua condição de refugiado nos Estados Unidos da América e o seu regresso à Lituânia, 24 anos depois de ter visto pela última vez sua família. Reminiscências é um filme em que o cineasta procura, no seu processo de rememoração, um entendimento mais profundo sobre a construção da sua própria identidade dentro de um contexto de pós-guerra. É o que acontece, por exemplo, quando o filme mostra imagens dele e do seu irmão, Adolfas, caminhando pelos bosques de Catskills, nos EUA, enquanto o cineasta comenta:

\begin{abstract}
No início daquele outono, em 1957 ou 1958, uma manhã de domingo, fomos aos Catskills, ao bosque. Caminhamos entre a folharada, afastando-a com uma vara. Andamos longamente, entramos no profundo do bosque. Foi bom caminhar, assim, sem pensar, sem pensar em nada sobre os últimos dez anos. E dizia a mim mesmo que poderia caminhar assim, sem pensar nos dez anos de guerra, na fome, no Brooklyn. E quase, e talvez, pela primeira vez, enquanto caminhamos pelo bosque, aquele dia de início de outono, foi a primeira vez que não me senti sozinho na América. Pensei que ali estavam o solo, a terra e as folhas; e as árvores e a gente, e que, da mesma maneira, eu estava, pouco a pouco, me convertendo como parte de tudo aquilo. Por um momento esqueci meu lugar. Este era o começo do meu novo lugar. "Me liberei das cordas do tempo, outra vez", disse a mim mesmo (MEKAS, 1972, 00 min. 01 seg., tradução nossa).
\end{abstract}

Ao evidenciar o caráter de testemunho, Mekas assume uma proposta narrativa que procura expor as fissuras que a guerra gerou na sua trajetória. Existe em Reminiscências tanto um desejo do cineasta em afirmar a sua condição de refugiado, como também em denunciar essa mesma condição vivida por milhares de pessoas. "Sim, ainda somos pessoas

1 Voz extradiegética (que não emerge da imagem, exterior à cena) que é utilizada para narrar, assumir um tom reflexivo ou contextualizar determinadas ações ou acontecimentos que as imagens mostram. 
refugiadas, inclusive hoje, o mundo está cheio de gente como nós. Todos os continentes estão cheios de refugiados" (07 min. 37 seg., tradução nossa), afirma Mekas, na mesma sequência, em que mostra imagens de refugiados que recém aportavam nos Estados Unidos, em 1950 (Fotogramas 03 e 04). Existe, na essência desse filme, uma busca mais atrelada ao cinema documentário, no sentido de querer demarcar um contexto sócio-histórico e revelar as impressões que essa realidade causou em Mekas. Tanto as imagens como os comentários ditos pelo cineasta estão em sintonia, no sentido de documentar e refletir sobre um determinado acontecimento.
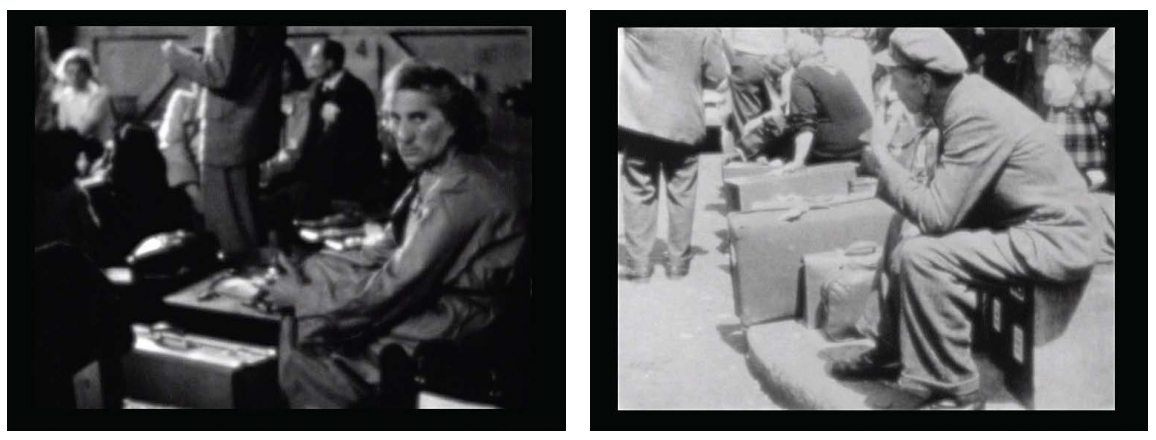

Fotograma 3. sequência do filme Reminiscências de uma Jornada à Lituânia (MEKAS, 1972). Fotograma 4. sequência do filme Reminiscências de uma Jornada à Lituânia (MEKAS, 1972)

No entanto, é interessante perceber como esta busca autorreflexiva do uso da voz em off também foi sofrendo transformações ao longo da obra do cineasta. Mekas é um cineasta que procura imprimir a passagem do tempo nos seus filmes-diário. Em Walden (MEKAS, 1964-1969), Reminiscências, Lost Lost Lost (MEKAS, 1976), a distância entre o período em que foram registradas as imagens e o período em que Mekas decidiu montá-las e finalizar o filme torna-se determinante nas suas escolhas narrativas. Quanto maior é o intervalo entre os registros e a montagem desses registros, mais se acentua um caráter ensaístico na sua abordagem e um estranhamento entre o Mekas-autor e o Mekasmontador que ressignifica essas imagens na moviola. Por outro lado, quanto menor é o período entre o registro das imagens e a montagem do filme, mais se ressalta o caráter confessional e documental sobre o que é dito no uso da voz em off: "As circunstâncias que envolvem esta reescrita são elas próprias sujeitas ao tempo, às mudanças da ideia que Mekas faz do formato de sua própria vida e de como esta poderia ser expressada como filme" (JAMES, 2013, p. 191). É justamente dentro desse processo de reencontro com as imagens que Mekas evidencia, na sua construção narrativa, as "espessuras" que a passagem do tempo imprime nos seus filmes-diário.

Conforme varia o período entre o passado e o presente no qual seus restos são contemplados, variam também os termos do diálogo possível entre cinegrafista e 
editor. Quanto maior a distância, maior a sensação de perda e maior a sensação de irrecuperabilidade do tempo, ao passo que quanto mais próxima for a montagem da filmagem, menor é a impressão da incidência dos flagelos do tempo. Assim sendo, as imagens de Walden, recentemente registradas no momento da sua montagem, apresentam questões inteiramente diferentes para o Mekas-montador do que as imagens do fim da década de 40 de Lost Lost Lost, que só foram montadas 30 anos após terem sido registradas. (JAMES, 2013, p. 191)

Se formos pensar, por exemplo, em Reminiscências, em que os registros fílmicos foram realizados em 1971 e o filme teve sua montagem finalizada em 1972, o processo reflexivo de Mekas está atrelado a questões mais empíricas ou a pequenos detalhes que reconstroem os acontecimentos. Assim como ocorreu no seu diário de exílio, que começou a escrever quando deixou o seu país durante o período da Segunda Guerra Mundial, a proximidade entre o acontecimento em si e a elaboração narrativa sobre esse acontecimento faz com que exista, na sua escrita, um caráter mais descritivo e menos divagador sobre o que é relatado. É o que ocorre, por exemplo, em uma sequência em que Mekas mostra imagens nos campos da granja coletiva Vienybé e do seu amigo de infância Petras, comentando com o uso da voz em off:

Decidimos sair a ver os campos para ver como se trabalha neles hoje em dia. Então, vamos. Petras nos guia. Está muito entusiasmado, quer nos ensinar tudo. E ali, encima de uma colheitadeira, está Jonas Ruplenas, com quem fui ao colégio, aquele que costumava ocupar-se das vacas e das ovelhas nos campos. E agora está aí sentado, é tão grande, a máquina é tão enorme e os campos são tão vastos. Nosso amigo Kostas canta uma canção sobre o trabalho coletivo na granja. Todos cantamos com ele. (MEKAS, 1972, 25 min. 59 seg., tradução nossa)

Por outro lado, quando a "espessura" entre o período em que as imagens foram registradas e o período em que foram montadas é maior, a abordagem narrativa nos filmes-diário do cineasta tende para uma busca mais ensaística. É o que ocorre, por exemplo, em filmes como Lost Lost Lost (com imagens registradas entre os anos de 1949 a 1962 e cuja montagem e finalização foi realizada em 1976) e As I was moving ahead occasionally I saw brief glimpses of beauty (MEKAS, 2000) (com imagens registradas entre os anos de 1973 a 1982 e o seu processo de montagem e finalização tendo ocorrido em 2000). Em ambos os filmes, a distância não consegue ser menor do que quatorze anos de intervalo entre o filmar e o montar. Menos preso em elucidar ou descrever em detalhes os eventos que são mostrados nesses filmes-diário, Mekas propõe-se a divagar, a refletir sobre um passado distante, a criar estranhamentos entre os arquivos fílmicos e o uso da voz em off.

Existem rupturas e descontinuidades entre a imagem e a fala que evidenciam uma busca desse cineasta em concentrar sua abordagem em um tom mais atrelado ao cunho ensaístico. À medida que vamos avançando cronologicamente sobre a sua obra fílmica, 
mais é possível descobrir como Mekas vai progressivamente buscando um processo de descontinuidade e desfiguração na construção do eu nos seus filmes-diário.

Considerando como exemplo o caso do filme As I was moving ahead, esse processo mostra-se ainda mais evidente. A começar pela introdução desse filme, dividido em 12 capítulos e com quase cinco horas de duração, Mekas logo trata de embaralhar um entendimento mais direto e objetivo sobre si próprio, quando afirma:

\begin{abstract}
Realmente, nunca fui capaz de discernir onde começa a minha vida e onde termina. Nunca fui capaz de saber nada sobre tudo isso. Sobre o que se trata, sobre o significado de tudo. Agora, quando comecei a reunir todos esses rolos de películas para juntá-los, a primeira ideia que me veio foi guardar sua ordem cronológica. Mas logo desisti e simplesmente comecei a juntá-los ao acaso, tal como os encontrava na estante. Porque realmente não sei a que pertence cada pedaço da minha vida. Que assim seja, que assim permaneça, puro acaso, desordem. Existe uma certa ordem (nos rolos de películas), uma ordem própria que realmente não compreendo, como nunca compreendi a vida ao meu redor, a vida real, como a chamam. Ou gente verdadeira, nunca as compreendi. (MEKAS, 2000, 00 min. 07 seg., tradução nossa)
\end{abstract}

Mekas afirma imprecisões, divaga sobre o real e sobre si mesmo, sem querer assumir o caráter incisivo das suas obras anteriores. Não por acaso, isso também está diretamente relacionado ao próprio contexto em que foi finalizado As I was moving ahead. No ano 2000, Mekas completava 51 anos vivendo nos EUA, o que correspondia a mais da metade da sua idade vivendo em solo americano. As imagens mostradas também remetem a um período em que ele já se afirmava como cidadão americano. Não só as imagens remetem ao que Mekas construiu em solo nova-iorquino (a sua família e as amizades como P. Adams Sitney, Allen Ginsberg, entre outros), como também se descola das imagens mostradas em Reminiscências e Lost Lost Lost, referentes aos seus primeiros anos nos EUA, quando o cineasta ainda buscava se inserir na sociedade americana.

No recorte temporal estabelecido em As I was moving ahead - que contradiz a sua afirmação de que as imagens foram montadas ao acaso e sem um ordenamento cronológico -, Mekas não procura mais concentrar a sua abordagem sobre a sua trajetória como refugiado, como o fez em Walden, Lost Lost Lost e Reminiscências, o que lhe interessa nesse filme-diário é mostrar a si próprio como um ensaísta, como alguém que procura refletir sobre as formas para se autorrepresentar. Mais do que saber quem é Mekas, entendemos de que forma ele procura afirmar-se em um processo que "se mantém na tensão entre eu penso e eu escrevo" (BELLOUR, 1997, p. 332).

As I was moving ahead é um filme-diário em que Mekas procura fazer menos referência a um contexto sociopolítico e mais ao seu processo solitário de montar os registros fílmicos. Mesmo sem revelar imagens da sua moviola, dos rolos de película ou do local onde monta essas imagens, o uso da voz em off faz com que se evidencie 
uma abordagem reflexiva sobre o processo de construção do filme. É o que ocorre, por exemplo, na sequência em que, ao mostrar imagens de arquivo de uma apresentação da sua filha Oona em uma Escola para Filhos de Artistas (Fotograma 05) e imagens do seu filho Sebastian apagando as velas da torta no seu aniversário (Fotograma 06), ele comenta:

Aqui estou com minhas imagens e meus sons, sozinho, numa casa praticamente vazia. Oona está agora casada, é feliz e vive no Brooklyn. Mas na verdade, neste mesmo instante, esta com Sebastian. Foram ao cinema. Hollis está fora, saiu logo cedo esta manhã. Eu saí antes dela, não sei onde está nem a que horas volta para casa. Aqui estou, sozinho com meus gatos, minhas imagens e meus sons. E comigo mesmo. Comigo mesmo, me perguntando, me fazendo perguntas sobre mim mesmo (MEKAS, 2000, 26 min. 14 seg., tradução nossa).
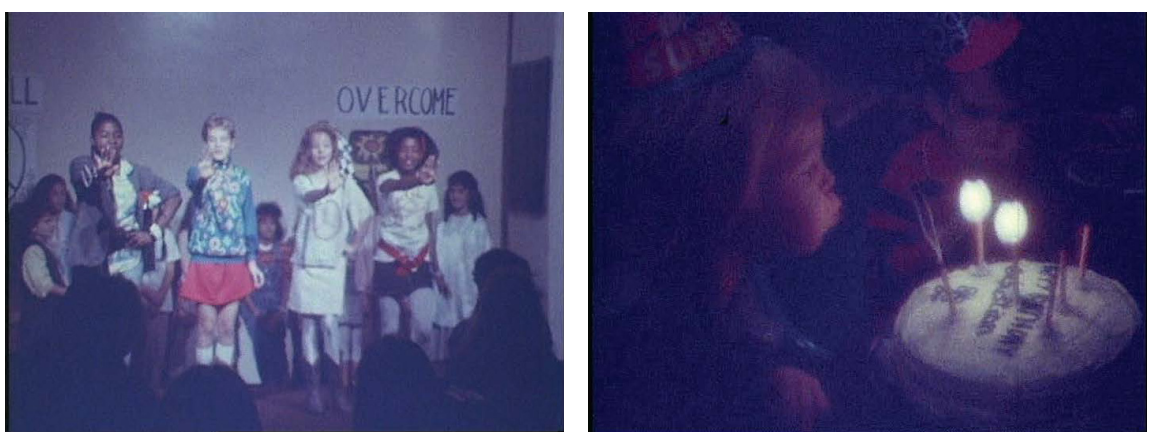

Fotograma 5. sequência do filme As I Was Moving Ahead (MEKAS, 2000). Fotograma 6. sequência do filme As I Was Moving Ahead (MEKAS, 2000)

Em um mesmo fragmento, Mekas mescla o contexto da sua família, o processo de elaboração do seu filme e a forma como ele próprio se insere entre ambos. Com comentários como esse, o cineasta pretende produzir um entendimento de que, para conhecer a sua biografia, é preciso antes conhecer as escolhas narrativas que constituem esse processo de autorrepresentação. Enquanto as imagens de As I was moving ahead revelam momentos da sua intimidade e dos seus amigos e familiares, o uso reflexivo da voz em off faz com que possamos nos aproximar de um entendimento dos códigos estéticos e narrativos que o cineasta procura construir no filme.

\section{Considerações finais}

Lidar com a questão da autorrepresentação é ingressar em um campo no qual não existe uma definição única sobre como um autor pode ou deve construir a si próprio dentro de um relato de cunho autobiográfico. Nesse processo de negociação, afirma-se intenções, 
estranhamentos, desfigurações que são responsáveis por operar um desprendimento entre o autor e as escolhas narrativas que decide assumir na obra. O eu se torna um outro, na mesma medida em que esse outro constrói uma representação sobre o eu.

Quando analisamos essas questões na esfera do diário e na sua relação com o cinema, o entendimento sobre o tema da autorrepresentação torna-se ainda mais imbricado, na medida em que envolve o uso da palavra, mas também a construção da imagem e a forma como ambas se relacionam entre si pela montagem. Com os seus filmes-diário, Mekas fez da sua obra um campo de experimentações para pensar não somente a sua condição autobiográfica (enquanto prisioneiro nos campos de concentração na Segunda Guerra Mundial e refugiado no período pós-guerra), mas, sobretudo, as implicações e escolhas narrativas criadas pelo processo de criação. Adepto de uma narrativa fragmentária, descontínua, que revela uma trajetória permanente de construção do eu, Mekas afirmou a sua busca artística por meio do diário e contribuiu, sobretudo, para pensar, de forma mais abrangente, a questão da autobiografia.

Para além do gênero autobiográfico, os seus filmes-diário privilegiam uma forma mais ensaística, ao buscar de maneira diversa a sua identidade sustentada pelas implicações que geram um processo autorreflexivo. Os seus filmes evidenciam um desejo de Mekas em adentrar a intimidade das suas imagens caseiras, em reencontrar momentos que marcaram a sua vida pessoal, ao mesmo tempo em que demonstram uma busca por ressignificar essas memórias.

Uma das características na sua obra é perceber de que forma se estabelece, no processo de montagem, o reencontro com seus arquivos fílmicos que acabam por construir distintas narrativas nos seus filmes-diário. Na maneira como decide resgatar um material que filmou há mais de vinte ou trinta anos em alguns dos seus filmes, é possível identificar como as "espessuras" temporais entre o registro e a sua montagem tornam-se determinantes na sua abordagem. Nesse processo, em que o uso da voz em off assume protagonismo, é possível distinguir um caminho que percorre desde um tom mais documental, como relatar as experiências vividas por meio de um acontecimento (o seu retorno à Lituânia, em Reminiscências de uma jornada à Lituânia), até um tom mais ensaístico em filmes em que a "espessura" do tempo entre o registro e a sua edição é maior (como ocorre em As I was moving ahead).

Nesse sentido, podemos afirmar que a obra de Jonas Mekas se tornou uma referência para a compreensão da autorrepresentação no cinema por meio do diário enquanto forma. Seja pela inscrição do tempo contida nos seus filmes e por uma procura ensaística que revela caminhos que não se reduzem a uma definição categórica sobre quem é, a sua obra não somente aprofunda um processo de reflexão sobre a construção do eu, mas acaba apontando caminhos para se pensar a linguagem cinematográfica. 
Cristiane Freitas Gutfreind é professora do PPGCom e da graduação em Cinema da Pontifícia Universidade Católica do Rio Grande do Sul (PUCRS). É bolsista de Produtividade em Pesquisa do CNPq.

cristianefreitas@pucrs.br

Rafael Valles é doutorando em Comunicação Social pela Pontifícia Universidade Católica do Rio Grande do Sul (PPGCom/PUCRS).

ra.valles@hotmail.com

\section{Referências}

BELLOUR, R. Entre-imagens. Foto. Cinema. Vídeo. São Paulo, Papirus Editora, 1997.

BERGALA, A. Si "yo" me fuera contado. In: GUTIÉRREZ, G. M. Cineastas frente al espejo. Madrid: T \& B Editores, 2008.

DUHART, O. G. Tiempo y escritura - el diário y los escritos autobiográficos de Luis Oyarzún. Santiago de Chile: Editorial Universitaria, 2009.

GONÇALVES, O. (Org.). Narrativas sensoriais. Rio de Janeiro: Editora Circuito, 2014.

JAMES, D. Diário em filme/ Filme-diário: prática e produto em Walden, de Jonas Mekas. In: MEKAS, J.; MOURÃO, P. (Org.). Jonas Mekas. São Paulo: Centro Cultural Banco do Brasil - USP, 2013. pp. 165-205.

LEJEUNE, P. O diário: gênese de uma prática. In: GUTFREIND, Cristiane Freitas (Org.). Narrar o biográfico: a comunicação e a diversidade da escrita. Porto Alegre: Sulina, 2015.

MEKAS, J. Ningún lugar adonde ir. Buenos Aires: Caja Negra Editora, 2008.

.Walden - Diaries, Notes \& Sketches. EUA, 1964-1969, 16mm, cor, 180 min.

Reminiscences of a journey to Lithuania (Reminiscências de uma jornada à Lituânia). EUA, 1972, 16mm, cor/p\&b, $82 \mathrm{~min}$.

Lost Lost Lost. EUA, 1976, 16mm, cor/p\%b, $180 \mathrm{~min}$.

cor, $288 \mathrm{~min}$

MOURÃO, P. Salve Jonas. In: MEKAS, J.; MOURÃO, P. (Org.) Jonas Mekas. São Paulo: Centro Cultural Banco do Brasil - USP, 2013.

RENOV, M. Lost Lost Lost: Mekas as Essayist. In: JAMES, D. To free the cinema: Jonas Mekas and the New York underground. New Jersey-EUA: Princeton University Press, 1992. pp. 215-239.

TURIM, M. Reminiscences, subjectivities, and truths. In: JAMES, David. To free the cinema: Jonas Mekas and the New York underground. Princeton, New Jersey - EUA: Princeton University Press, 1992. 